\title{
Utilization of Ores with High Combined Water Content for Ore-carbon Composite and Iron Coke
}

\author{
Taichi MURAKAMI and Eiki KASAI
}

Formerly Institute of Multidisciplinary Research for Advanced Materials, Tohoku University, Sendai, 980-8577 Japan. Now at Graduate School of Environmental Studies, Tohoku University, Sendai, 980-8579 Japan.

(Received on November 25, 2010; accepted on February 22, 2011)

Reduction of $\mathrm{CO}_{2}$ emissions and effective use of low-grade iron resources are very important tasks for the steel industry. One of the methods to simultaneously achieve both is to lower the thermal reserve zone temperature in the blast furnace using a high-reactivity agglomerate such as an iron ore-carbon composite or iron coke in which the iron source is an ore with high combined water content. In this study, using high water content ores, the effects of the ore particle size and coal-ore mixture ratio in a composite on the reduction behavior were investigated. The impact of the ore particle size in iron coke on the gasification behavior was also investigated.

A decrease in the ore particle size in the composite and an increase in the coal-ore mixture ratio lowered the temperature at which metallic iron starts to form. However, compared with hematite ore, weaker particle size and mixture ratio dependencies were obtained for composites made from ore having high combined water content.

The utilization of an ore with high combined water content as the iron source is an effective method for lowering the temperature at which the gasification of iron coke begins. This temperature is about $20 \mathrm{~K}$ and $50 \mathrm{~K}$ lower than that when using coke with hematite ore and using coke only, respectively.

KEY WORDS: ironmaking; combined water; catalytic effect; metallic iron; gasification of carbon.

\section{Introduction}

Today, the world steel industry accounts for approximately $10 \%$ of total global anthropogenic greenhouse gas emissions. ${ }^{1)}$ In Japan, however, where steel production is the nation's main industry, it accounts for approximately $15 \%$. The ironmaking process consumes a huge amount of fossil fuel, and so discharges greenhouse gases, particularly $\mathrm{CO}_{2}$. Therefore, an innovation in ironmaking is highly desirable to decrease $\mathrm{CO}_{2}$ emissions. Lowering the thermal reserve zone temperature in the blast furnace by decreasing the distance between the iron oxide and carbonaceous particles may be one of the effective ways to achieve this. Mixed charging of iron ore with coke in the blast furnace, ${ }^{2)}$ the utilization of highly reactive coke such as iron coke, ${ }^{3)}$ and the utilization of iron ore-carbon composites ${ }^{4)}$ have attracted significant attention.

A number of studies have been conducted on the reduction behavior of composites of iron oxide and carbonaceous materials. Kondo et al. studied the gasification and reduction behavior of a composite of the powder mixture of hematite ore and coke at a heating rate of $20 \mathrm{~K} / \mathrm{min} .{ }^{5)} \mathrm{Kasai}$ et al. studied the effect of hot briquetting composite charging of the blast furnace on the thermal reserve zone temperature and the ratio of $\mathrm{CO}$ gas utilization. ${ }^{4)}$ When conventional sintering was used, the thermal reserve zone temperature was estimated at $1323 \mathrm{~K}$.

The properties of available natural resources such as iron ore and coal will rapidly change due to the depletion of high-grade resources. ${ }^{6)}$ Australian Marra Mamba and pisolitic ores, which are classified as low-grade ores, must now be extensively used. These ores contain higher amounts of gangue minerals as well as combined water since their major component is goethite, $\mathrm{FeOOH}^{7}{ }^{7}$ ) In a previous study, ${ }^{8)}$ our group evaluated the effect of combined water content on the reduction behavior of iron ore-coal composites at elevated temperatures under an inert gas flow. However, the effects of the ore particle size and the mixture ratio of carbonaceous materials to iron ore were not clarified.

There have been a number of reports ${ }^{3,9)}$ on production technology for iron coke and its properties. The addition of catalytic iron powder to coal before carbonization increases the reactivity of coke, but also decreases its strength. The degree of reactivity depends on the types of iron sources added to the coal, such as metallic iron and iron oxides. The reason for these differences, however, remains unclear. Iron ore fines are preferred because of the production cost. However, the effect of the particle size of iron ore on the reactivity of iron coke has not been evaluated.

In this study, the possibility of the effective utilization of low-grade iron ore as the iron source for ore-carbonaceous material composite and iron coke was explored. For utilization of the composite, the effects of the particle size of the ore and the mixture ratio of carbonaceous materials to ore on the reduction and gasification behaviors were clarified. In addition, for the utilization of iron coke, we evaluated the 
effects of the ore type and particle size on the temperature at which gasification begins.

\section{Experimental}

\subsection{Raw Materials}

Four types of iron ore were prepared - one hematite $(\mathrm{H})$, one Marra Mamba (M), and two pisolitic (P1 and P2) oreswhose chemical composition and loss on ignition (LOI) are shown in Table 1, along with noncoking coal (VM: 36\%, fixed carbon: $56 \%$, ash: $8 \%$ ) as the carbonaceous material. Six particle size categories were used for the iron ore raw material for the composite. In addition, commercially available hematite reagents with average particle sizes of $0.6,26$, and $150 \mu \mathrm{m}$ were prepared. The particle size of the coal was adjusted to $<44 \mu \mathrm{m}$. For iron coke, the particle sizes of the ores and coal were $<250$ and $<100 \mu \mathrm{m}$, respectively.

\subsection{Reduction Experiment for Composite}

The molar ratio of fixed carbon in the coal to oxygen $(\mathrm{C} / \mathrm{O})$ in the iron oxide was maintained in a range from 0.8 to 2.7 . Powders of the ore and coal were well mixed without reducing the particle size. Then, the mixed powder was pressshaped under a pressure of $9.8 \times 10^{7} \mathrm{~Pa}$. A composite sample was thus obtained with a diameter of $10 \mathrm{~mm}$ and a height of $10 \mathrm{~mm}$. Figure 1 shows a schematic diagram of the experimental system used for the reduction of the composite; the details of this apparatus have been reported previously. ${ }^{8)}$ The ore-coal composite sample was placed in the holder. After evacuating the air from the chamber, $\mathrm{Ar}-5 \% \mathrm{~N}_{2}$ gas was then introduced at a rate of $8.33 \times 10^{-6} \mathrm{~N} \mathrm{~m}^{3} / \mathrm{s} . \mathrm{N}_{2}$

Table 1. Chemical compositions of iron ores used.

\begin{tabular}{c|c|c|c|c|c|c}
\hline \multirow{2}{*}{} & \multicolumn{7}{|c|}{$\mathrm{T}-\mathrm{Fe}$} & $\mathrm{SiO}_{2}$ & $\mathrm{Al}_{2} \mathrm{O}_{3}$ & $\mathrm{CaO}$ & $\mathrm{MgO}$ & LOI \\
\cline { 2 - 7 }$(\mathrm{mass} \%)$ \\
\hline $\mathrm{H}$ & 68.04 & 1.32 & 0.74 & 0.01 & 0.01 & 0.52 \\
\hline $\mathrm{M}$ & 59.94 & 3.69 & 2.70 & 0.02 & 0.04 & 7.76 \\
\hline $\mathrm{P} 1$ & 59.41 & 5.05 & 1.19 & 0.02 & 0.06 & 8.75 \\
\hline $\mathrm{P} 2$ & 57.16 & 5.51 & 2.54 & 0.01 & 0.09 & 10.13 \\
\hline
\end{tabular}

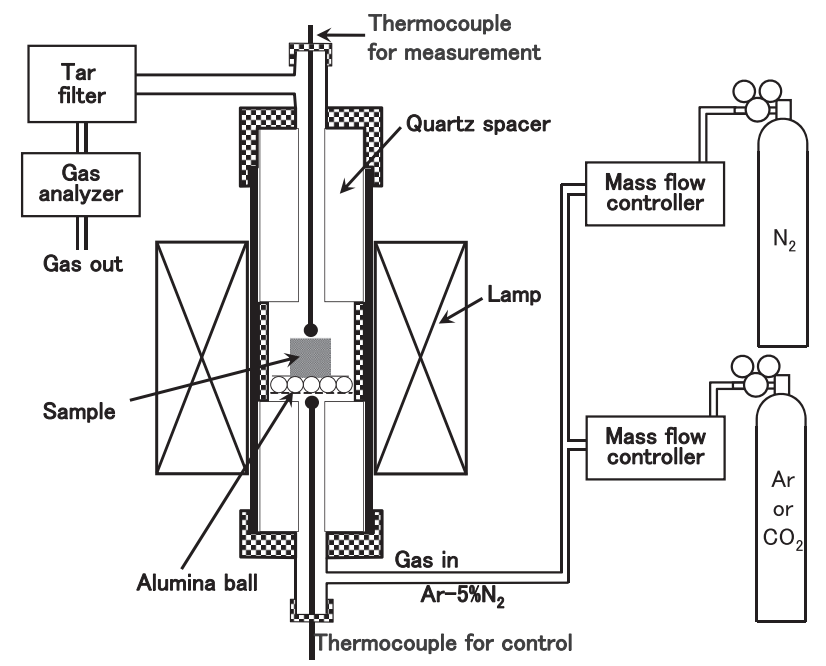

Fig. 1. Schematic diagram of experimental apparatus used for reduction of composite. gas was used as a tracer to estimate the amount of gas generated from the composite. The chamber was then heated up to $1573 \mathrm{~K}$ at a heating rate of $0.33 \mathrm{~K} / \mathrm{s}$ using an infrared image furnace. The temperature was measured at a height of $1 \mathrm{~mm}$ from the composite sample using a $\mathrm{Pt} / \mathrm{Pt}-13 \% \mathrm{Rh}$ thermocouple. The concentrations of $\mathrm{CO}$ and $\mathrm{CO}_{2}$ in the outlet gas were continuously measured using infrared gas analyzers. The concentrations of $\mathrm{CO}, \mathrm{CO}_{2}, \mathrm{H}_{2}, \mathrm{H}_{2} \mathrm{O}, \mathrm{CH}_{4}$, $\mathrm{C}_{2} \mathrm{H}_{4}, \mathrm{C}_{2} \mathrm{H}_{6}$, and $\mathrm{N}_{2}$ gases were also measured by gas chromatography.

In order to estimate the gasification behavior of coal, an $\mathrm{Al}_{2} \mathrm{O}_{3}$-coal composite was prepared in which the volume of $\mathrm{Al}_{2} \mathrm{O}_{3}$ was the same as that of the ores in the composites. In addition, a tablet of the ores was also prepared and used to estimate their gas generation behavior such as via the thermal decomposition of $\mathrm{FeOOH}$. The reduction degree of iron oxide in the composite was calculated by estimating the amount of these gases by the following formula.

$$
R D(T)=\frac{\int_{T_{0}}^{T} n_{\text {comp }} d T-\int_{T_{0}}^{T} n_{\text {ore }} d T-\int_{T_{0}}^{T} n_{\text {coal }} d T}{n_{\text {oxide }}} \times 100
$$

Here, $n_{\text {comp }}$ and $n_{\text {coal }}$ are the molar amounts of atomic oxygen in the $\mathrm{CO}, \mathrm{CO}_{2}$ and $\mathrm{H}_{2} \mathrm{O}$ gases generated from the composite and that form coal, respectively; and $n_{\text {ore }}$ and $n_{\text {oxide }}$ are the molar amounts of atomic oxygen in $\mathrm{H}_{2} \mathrm{O}$ generated from the ore and that which was originally contained in the iron oxide in the composite, respectively. $T_{0}$ is the initial experimental temperature. The gasification rate was calculated from the change in the amount of $\mathrm{CO}$ and $\mathrm{CO}_{2}$ gas in the ore-coal and $\mathrm{Al}_{2} \mathrm{O}_{3}$-coal composites.

The microstructures of the composite sample were observed using a scanning electron microscope (SEM).

\subsection{Preparation of Iron Coke and Gasification Test}

Coal powder was mixed well with 30 mass $\% \mathrm{H}$ ore without reducing the particle size. The additive amounts of the other ores were controlled in same way as $\mathrm{C} / \mathrm{O}$ was controlled in case of the $\mathrm{H}$ ore. The mixed powder was pressshaped, as described above. For the carbonization treatment, the tablet sample was heated up to 1073,1173 , and 1273 $\mathrm{K}$ at a heating rate of $8.33 \times 10^{-2} \mathrm{~K} / \mathrm{s}$ under an $\mathrm{Ar}-5 \% \mathrm{~N}_{2}$ gas at a flow rate of $8.33 \times 10^{-6} \mathrm{~N} \mathrm{~m}^{3} / \mathrm{s}$, and held at that temperature for $7.2 \mathrm{ks}$. The temperature was measured at a height of $1 \mathrm{~mm}$ from the composite sample using a Pt/Pt$13 \% \mathrm{Rh}$ thermocouple. The concentration of gas was measured by the abovementioned methods. After carbonization, a cross section of the sample was observed using SEM.

For the gasification test, the carbonized sample was heated up to $1273 \mathrm{~K}$ at a heating rate of $8.33 \times 10^{-2} \mathrm{~K} / \mathrm{s}$ under $\mathrm{CO}_{2}-$ $5 \% \mathrm{~N}_{2}$ gas at a flow rate of $8.33 \times 10^{-6} \mathrm{~N} \mathrm{~m}^{3} / \mathrm{s}$, and then held at that temperature for $1.8 \mathrm{ks}$. The gasification behavior was monitored by the abovementioned methods.

\section{Results and Discussion}

\subsection{Lowering Reduction Temperature of the Com- posite Using High Combined Water Content Ore}

3.1.1. Reduction Behavior of the Composite

Figure 2 shows the changes in the generation rate of 


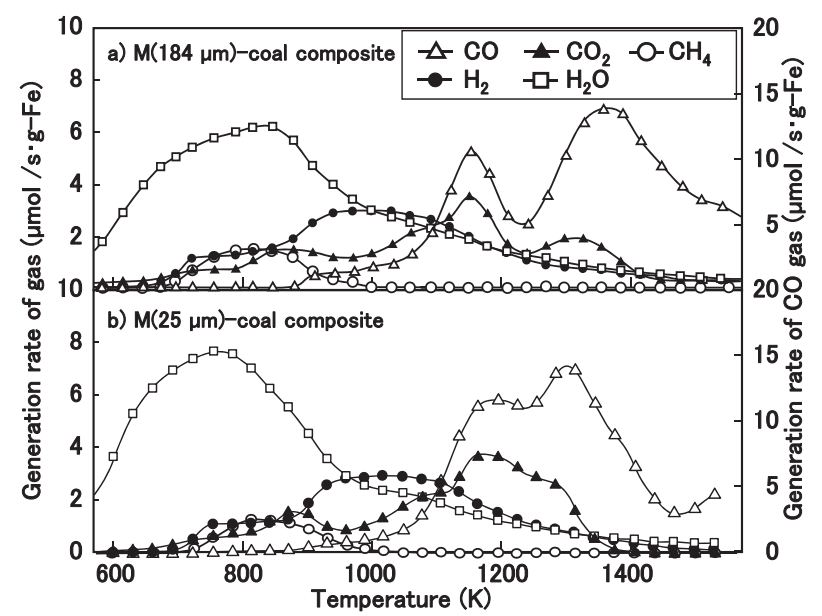

Fig. 2. Changes in the generation rates of gases from M-coal composites with temperature. The average particle sizes of $\mathrm{M}$ are a) 184 and b) $25 \mu \mathrm{m}$.

gases from the M-coal composite with temperature. The vertical axis on the right-hand side represents only the generation rate of $\mathrm{CO}$ gas, because a greater amount of $\mathrm{CO}$ gas than other gases generated at high temperature. Above 700 $\mathrm{K}, \mathrm{CH}_{4}$ gas starts to generated from coal because it contains volatile matter, and the generation rate of $\mathrm{CH}_{4}$ gas was the maximum, at approximately $820 \mathrm{~K} . \mathrm{C}_{2} \mathrm{H}_{4}$ and $\mathrm{C}_{2} \mathrm{H}_{6}$ gases were also detected, though the generation rate of these gases was lower than that of $\mathrm{CH}_{4}$ gas. $\mathrm{H}_{2}$ and $\mathrm{CO}_{2}$ gases sequentially generate from the composite, and the local maximum values of the generation rates of $\mathrm{CO}_{2}$ and $\mathrm{H}_{2}$ gases are at approximately 920 and $1040 \mathrm{~K}$, respectively. After the dehydration of the combined water, water vapor generates continuously during heating. These results suggest that the reduction reaction of iron oxide by carbon and hydrogen, which were produced from the volatile matter present in coal, proceeded below $1100 \mathrm{~K}^{8}{ }^{8}$

The generation rate of $\mathrm{CO}$ gas from the M-coal composite shows the local maximum value at approximately $1160 \mathrm{~K}$; however, the generation rate of $\mathrm{CO}$ gas from the H-coal composite remained constant up to this temperature. ${ }^{8)}$ The peak value of the generation rate increases with a decrease in the particle size of the iron ore. However, the peak value of the CO gas generation rate obtained above $1300 \mathrm{~K}$ decreases with decreasing the ore particle size.

\subsubsection{Effect of Iron Ore Particle Size on Reduction Behavior}

Figure 3 shows the changes in the gasification rate for Mcoal composites and the reduction degree with temperature. The average particle sizes of $\mathrm{M}$ ore were 5, 25, 45, and 184 $\mu \mathrm{m}$. The gasification rate indicates the total value of the generation rate of $\mathrm{CO}$ and $\mathrm{CO}_{2}$. At approximately $700 \mathrm{~K}$, an increase in the gasification rate is obtained due to the beginning of $\mathrm{CO}_{2}$ generation. There is no particle size dependence with the gasification. The major reactions with an increase in the molar amount of $\mathrm{CO}$ and $\mathrm{CO}_{2}$ are as follows.

$$
\begin{gathered}
\mathrm{C}_{(\mathrm{s})}+\mathrm{CO}_{2(\mathrm{~g})}=2 \mathrm{CO}_{(\mathrm{g})} \ldots \ldots \ldots \ldots \\
\mathrm{C}_{(\mathrm{s})}+\mathrm{H}_{2} \mathrm{O}_{(\mathrm{g})}=\mathrm{CO}_{(\mathrm{g})}+\mathrm{H}_{2(\mathrm{~g})} \ldots \\
\mathrm{CH}_{4(\mathrm{~g})}+\mathrm{H}_{2} \mathrm{O}_{(\mathrm{g})}=\mathrm{CO}_{(\mathrm{g})}+3 \mathrm{H}_{2(\mathrm{~g})}
\end{gathered}
$$

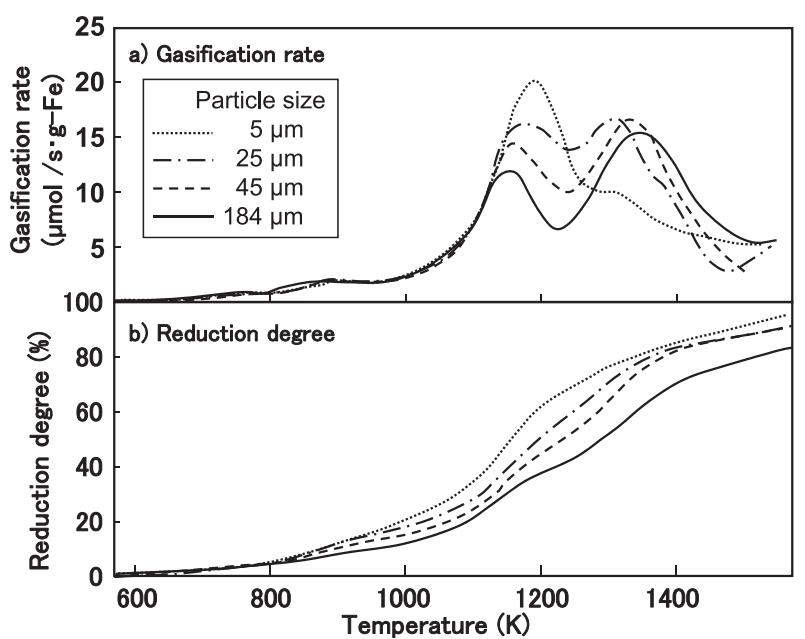

Fig. 3. Changes in a) gasification rates from M-Coal composites with various particle sizes, and b) reduction degree with temperature.

$$
\mathrm{C}_{(\mathrm{s})}+3 \mathrm{Fe}_{2} \mathrm{O}_{3(\mathrm{~s})}=\mathrm{CO}_{(\mathrm{g})}+2 \mathrm{Fe}_{3} \mathrm{O}_{4(\mathrm{~s})}
$$

A decrease in the particle size of iron ore allowed an increase in the number of contact points between the iron ore and coal because the number of the iron ore increases. However, this effect of particle size on the gasification behavior in this temperature range was not observed. This indicates that the amount of $\mathrm{CO}$ generation caused by the direct reduction reaction described in Eq. (5) is small. However, except Eq. (5), the other reactions, Eqs. (2)-(4), do not involve iron oxide. Therefore, it seems that these reactions increase the gasification rate.

Above $1000 \mathrm{~K}$, there is an increase in the gasification rate, which displays two peaks. The first peak moves toward the high-temperature side with decreasing ore particle size, and the peak value also increases. The second peak moves toward the low-temperature side with increasing ore particle size, though the lowest temperature is approximately 1310 K.

Similar reduction behaviors are observed in all the composites, as shown in Fig. 3(b). Reduction degree starts to increase at approximately $700 \mathrm{~K}$. The rate of the increase in the reduction degree changes at approximately $1100 \mathrm{~K}$ and $1200 \mathrm{~K}$. Above $1400 \mathrm{~K}$, an obvious decrease in the reduction rate is obtained. Particle size dependence becomes observable above $800 \mathrm{~K}$, and reduction degree decreases with an increase in particle size.

The relation between the temperature at which the reduction degree of the composites reached $30 \%$ and $80 \%$ and the average particle size of the iron ores are shown in Fig. 4, together with the results obtained using hematite reagents. A $30 \%$ reduction degree indicates that metallic iron starts to form in the composite. The temperature, at which metallic iron starts to form, decreases with decreasing ore particle size. This particle size dependence, however, is different for hematite and for high combined water content ores, and the latter has small dependence. Compared to an average particle size of $200 \mu \mathrm{m}$, the temperature at which metallic iron formation of a composite of M and P1 ores starts is $140 \mathrm{~K}$ lower than the temperature for $\mathrm{H}$ ore. However, the difference between the two ores that have a size of a few 
micrometers becomes small. The reason for this is that the effect of the increase in the specific surface area caused by the decrease in particle size becomes small because the effective surface area for the reduction reaction is increased by the formation of nano-sized pores in the high combined water content ore after the dehydration. Accordingly, the utilization of high combined water content ore with an average particle size of $200 \mu \mathrm{m}$ displays the same effect on lowering the reduction temperature when hematite ore with a size of $2 \mu \mathrm{m}$ is used.

The temperature, at which metallic iron started to form, of the composite using $\mathrm{M}$ and P1 ore was from 1100 to $1150 \mathrm{~K}$. This corresponds pretty much to the temperature, at which the gasification rate starts to increase abruptly. The gas concentration of $\mathrm{CO}$ and $\mathrm{CO}_{2}$ at this temperature range was almost same as the equilibrium gas concentration of this chemical reaction (6) at $101325 \mathrm{~Pa}$, as shown in the previous study in case of the average particle size of $184 \mu \mathrm{m} .{ }^{8)}$

$$
\mathrm{FeO}(\mathrm{s})+\mathrm{CO}_{(\mathrm{g})}=\mathrm{Fe}_{(\mathrm{s})}+\mathrm{CO}_{2(\mathrm{~g})}
$$

Watanabe et al. reported that the gasification rate of biomass char treated with fine iron oxide powder at $1173 \mathrm{~K}$ became higher than that of biomass char in pressure ratio of $\mathrm{CO}$ to $\mathrm{CO}+\mathrm{CO}_{2}$ of approximately 0.7 , which is equivalent to this equilibrium gas concentration, because metallic iron formed by the reduction of iron oxide acted as a catalyst of the gasification reaction described as Eq. (2). ${ }^{10)}$ It is estimated that the former peak of the gasification rate obtained in this study appears due to same mechanism as the behavior reported by Watanabe et al. Moreover, the temperature, at which the gasification rate started to increase again, was similar to that $\mathrm{CO}$ gas concentration started to increase from the equilibrium value of Eq. (6). It indicates that the reaction rate of gasification reaction of Eq. (2) became faster than that of reduction reaction of Eq. (6). Despite the physical property of ore ${ }^{8)}$ and its particle size, these temperatures corresponded with each other. Accordingly, this second increase in the gasification rate is caused by the increase in the reaction rate of Eq. (2). And, a decrease in the gasification rate after showing the peak is caused by the decrease in the reduction rate of the ore, which led to decreasing the amount of generated $\mathrm{CO}_{2}$ gas.

On the other hand, the temperature at which the reduction degree reaches $80 \%$ does not change when ore whose size is less than $20 \mu \mathrm{m}$ is used. The effect of the ore type is not obtained. The microstructures of the $\mathrm{Fe}_{2} \mathrm{O}_{3}$-coal composite heated at 1073 and $1373 \mathrm{~K}$ are shown in Fig. 5. The average particle size of the hematite reagent is $0.6 \mu \mathrm{m}$. In both microstructures, the size of the observed particle is completely different from its original size before heating. At $1373 \mathrm{~K}$, metallic iron particles with a size of approximately $10 \mu \mathrm{m}$ were observed. From this result, it seems that the original fine hematite powder agglomerates as secondary particles. The agglomerated secondary particles of iron oxide have a high specific surface area because of its porous structure, as shown in Fig. 5(a). At a lower temperature, therefore, the high reducing ability of iron oxide caused by decreasing the particle size is maintained. The formed metallic iron, however, sinters together when the metallization ratio increases at a high temperature. The remaining iron oxide particles are taken up by the formed metallic iron,

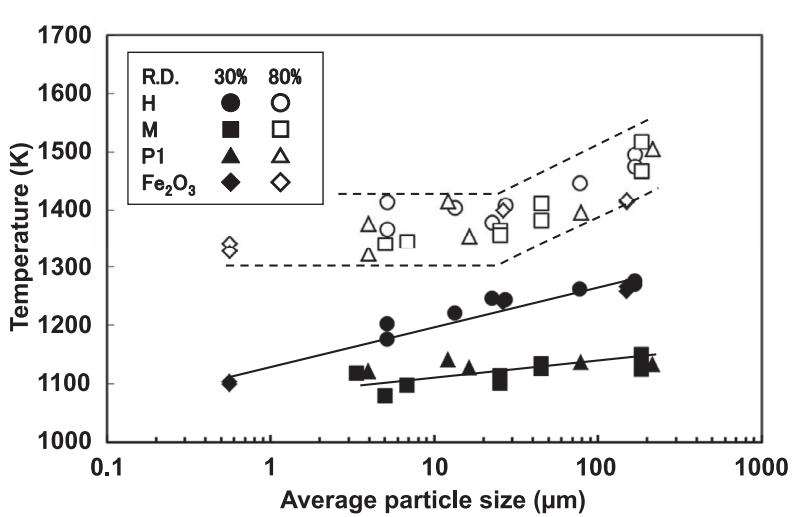

Fig. 4. Relation between temperature at which reduction degree reaches $30 \%$ and $80 \%$ and average particle size of ore in component.
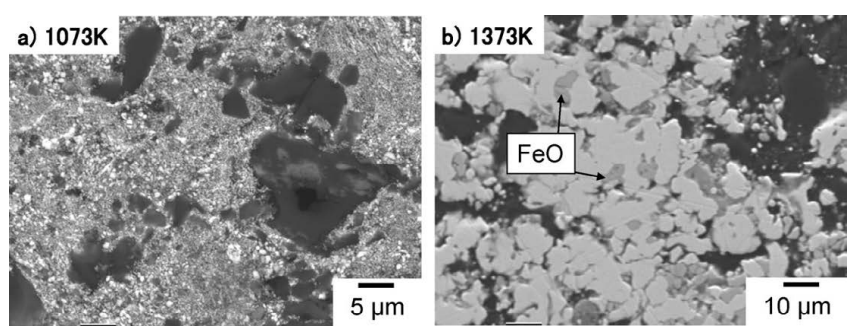

Fig. 5. Microstructure of the $\mathrm{Fe}_{2} \mathrm{O}_{3}$-coal composite heated at 1073 and $1373 \mathrm{~K}$.

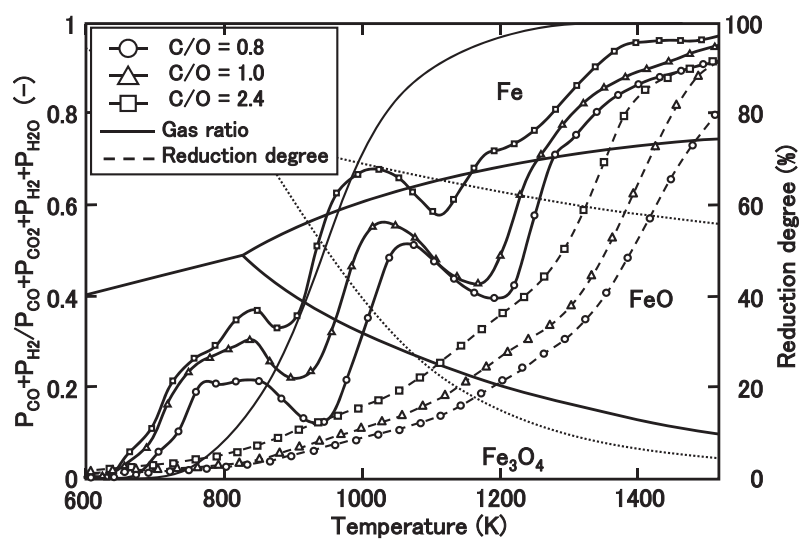

Fig. 6. Change in reduction degree and pressure ratio of $\left[\mathrm{CO}_{2}+\mathrm{H}_{2}\right]$ to $\left[\mathrm{CO}+\mathrm{CO}_{2}+\mathrm{H}_{2}+\mathrm{H}_{2} \mathrm{O}\right]$ in outlet gas generated from $\mathrm{H}$ coal composite with different mixture ratios of coal and ore with an increase in temperature on the phase relation of $\mathrm{Fe}-$ O system.

which decreases the specific surface area of the iron oxide. Therefore, it is considered the effect that the decrease in the particle size of iron oxide has on the reduction disappears.

\subsubsection{Effect of Mixture Ratio of Coal to Ore}

Figure 6 shows the changes in the partial pressure ratio of $\left(\mathrm{CO}+\mathrm{H}_{2}\right)$ to $\left(\mathrm{CO}+\mathrm{CO}_{2}+\mathrm{H}_{2}+\mathrm{H}_{2} \mathrm{O}\right)$ in the outlet gas generated from the $\mathrm{H}$-coal composites with various $\mathrm{C} / \mathrm{O}$, and the reduction degree with increasing temperature on a phase diagram of an $\mathrm{Fe}-\mathrm{O}$ system. The average particle size of $\mathrm{H}$ ore is $167 \mu \mathrm{m}$. Hereafter, this partial pressure ratio is described as the gas ratio. The gas ratio for the composite with all mixture ratios shows two peak values at approximately $800 \mathrm{~K}$ and $1000 \mathrm{~K}$. These peak values of the gas 
ratio increase with an increase in the mixture ratio. Namely, the reducing potential, which means a high gas ratio, increases with increasing $\mathrm{C} / \mathrm{O}$ in all temperature ranges. The reduction degree of the composite with a high $\mathrm{C} / \mathrm{O}$ starts to increase at a lower temperature.

The relation between the temperature at which the reduction degree of the composites reached $30 \%$ and $80 \%$ and $\mathrm{C} / \mathrm{O}$ is shown in Fig. 7. The temperature, at which metallic iron starts to form, decreases with increasing $\mathrm{C} / \mathrm{O}$. H-coal composite has a strong dependence on $\mathrm{C} / \mathrm{O}$ at lower coal content. Although the temperature at which metallic iron starts to form is $1273 \mathrm{~K}$ for a $\mathrm{C} / \mathrm{O}$ of 0.8 , the temperature is below $1170 \mathrm{~K}$ when $\mathrm{C} / \mathrm{O}$ becomes higher than 1.5 , which means that the amount of coal is 39 mass\%. Namely, an increase in $\mathrm{C} / \mathrm{O}$ from 0.8 to 1.5 could reduce the temperature at which metallic iron started to form by more than $100 \mathrm{~K}$. The reason for this is as follows. The increase in $\mathrm{C} / \mathrm{O}$ produces an increase in the amount of reducing gas from the coal in the composite. The amount of $\mathrm{CO}_{2}$ and $\mathrm{H}_{2} \mathrm{O}$ generated by the reduction reaction decreases because of a decrease in the amount of iron ore. Accordingly, the reducing potential in the composite increases, as described above. However, with high combined water content ore, the effect on the lowering of the beginning temperature is small, since this temperature is low even at a low $\mathrm{C} / \mathrm{O}$.

At a low $\mathrm{C} / \mathrm{O}$, the temperature, at which the reduction degree reaches $80 \%$, for the composite using high combined water content ore is higher than that for the H-coal composite. This temperature decreases with increasing $\mathrm{C} / \mathrm{O}$. However, when $\mathrm{C} / \mathrm{O}$ is higher than 1.3 , this trend is reversed, and this temperature becomes lower than $1400 \mathrm{~K}$. The reason for this is that the slag, which has a low reducing

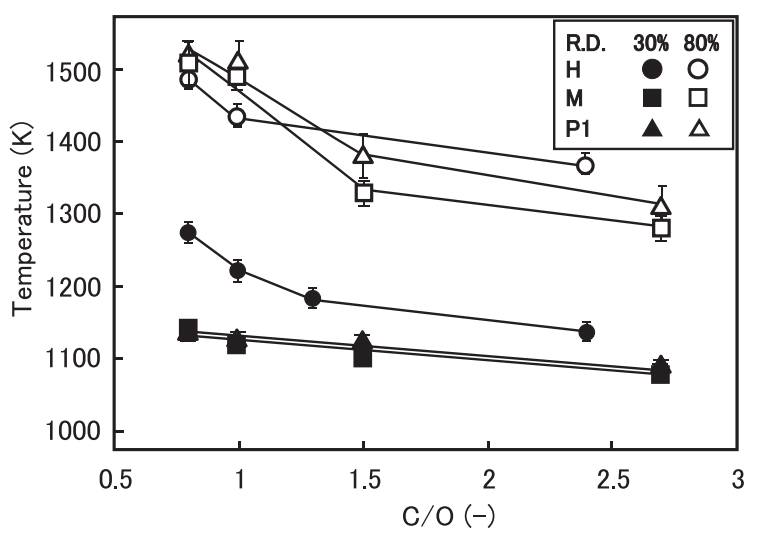

Fig. 7. Relation between temperature at which reduction degree reaches 30 and $80 \%$ and ratio of carbon to oxygen, $\mathrm{C} / \mathrm{O}$ in composite. ability, started to form at approximately $1373 \mathrm{~K}$ because the $\mathrm{FeO}$ formed by the reduction of $\mathrm{Fe}_{3} \mathrm{O}_{4}$ reacts with the gangue in the ore, thus decreasing the reduction rate. ${ }^{8)}$ These results indicate that to lower the reduction temperature of the composite using high combined water content ore, it is desirable to complete the reduction reaction at a temperature below $1373 \mathrm{~K}$.

\subsection{Lowering the Gasification Temperature of Iron Coke}

3.2.1. Microstructure and Reduction Degree after Carbonization

Figure 8 shows the microstructure of the iron coke prepared using $\mathrm{H}, \mathrm{M}$ and $\mathrm{P} 2$ ores after coking at $1273 \mathrm{~K}$. Iron ore with a particle size of less than $250 \mu \mathrm{m}$ was used. Many metallic iron particles were observed from a piece of particle ore. Figure 9 shows the relation between the reduction degree of iron ore in the iron coke that was obtained using different ores and coking temperatures. The reduction degree was calculated under the assumption that all the combined water in the ore and oxygen in the coal were emitted during the carbonization process. It was confirmed that the reduction degree calculated at $1073 \mathrm{~K}$ was in good agreement with the result determined by chemical analysis. The reduction degree increases with increasing coking temperature, reaching $95 \%$ of reduction degree at $1273 \mathrm{~K}$. The reduction degree of iron coke using hematite reagent was also high, the same as that obtained using ores.

\subsubsection{Effect of Particle Size of Metallic Iron on Gasifica- tion Behavior}

Figure 10 shows the change in the rate of $\mathrm{CO}$ gas gener-

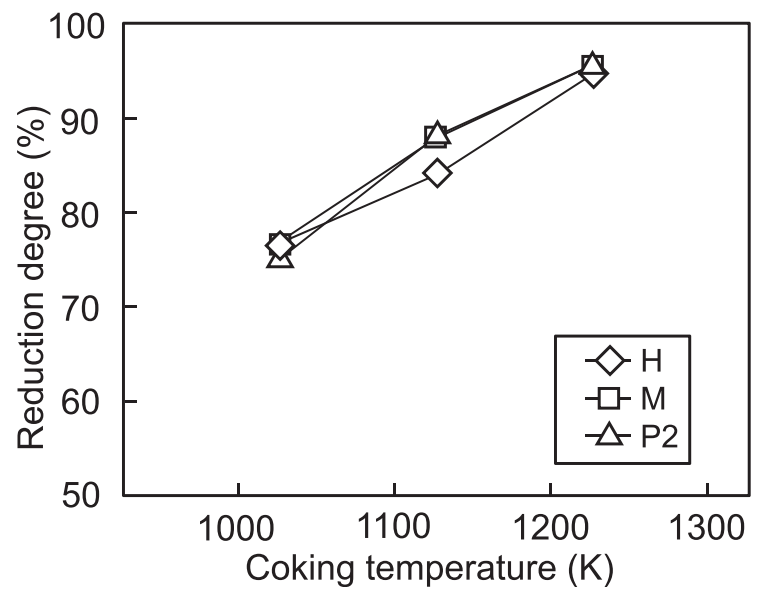

Fig. 9. Relation between reduction degree of iron ore in iron coke with the use of different ores and temperatures.
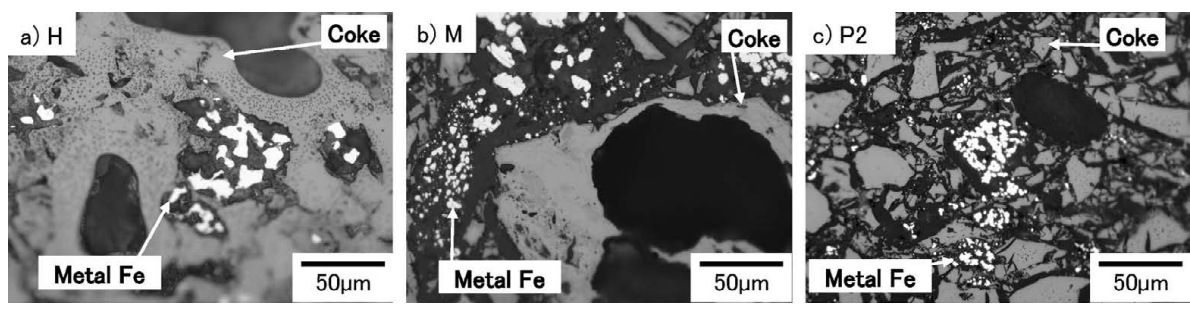

Fig. 8. Microstructure of iron coke using a) H, b) M, and c) P2 ores after coking at $1273 \mathrm{~K}$. 


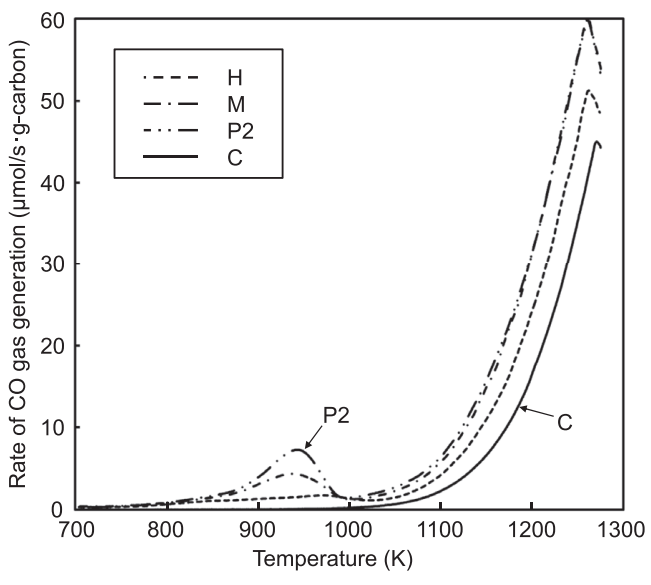

Fig. 10. Change in rate of $\mathrm{CO}$ gas generation of iron coke with the use of different ores produced in an image furnace at 1073 , with temperature.

ation obtained with iron coke using different ores, as produced in the furnace at $1073 \mathrm{~K}$, with temperature. The result of coke without the addition of ore, which is indicated by the legend symbol "C", is also shown. The vertical axis represents the gasification rate per gram of carbon remaining in the sample after the carbonization process. The amount of carbon after carbonization was calculated from the gas concentration generated from the sample during carbonization and the sample weight after carbonization. $\mathrm{CO}$ gas starts to generate from iron coke at $750 \mathrm{~K}$. The rate of $\mathrm{CO}$ gas generation shows a local peak value at approximately $940 \mathrm{~K}$, and then it decreases with increasing temperature. This peak value increases with increasing the amount of combined water in the original ore. No peak is produced from coke $\mathrm{C}$ at this temperature. It seems that this gasification is caused by the re-oxidation reaction of metallic iron under a $\mathrm{CO}_{2}$ gas atmosphere, as described by Eqs. (7) and (8).

$$
\begin{gathered}
3 \mathrm{Fe}_{(\mathrm{s})}+4 \mathrm{CO}_{2(\mathrm{~g})}=\mathrm{Fe}_{3} \mathrm{O}_{4(\mathrm{~s})}+4 \mathrm{CO}_{(\mathrm{g})}\left(\mathrm{T} \leq 570^{\circ} \mathrm{C}\right) \ldots . .(7) \\
\mathrm{Fe}_{(\mathrm{s})}+\mathrm{CO}_{2(\mathrm{~g})}=\mathrm{FeO}_{(\mathrm{s})}+\mathrm{CO}_{(\mathrm{g})}\left(\mathrm{T} \geq 570^{\circ} \mathrm{C}\right) \ldots \ldots . .(8)
\end{gathered}
$$

A further increase in the temperature allows the rate of $\mathrm{CO}$ gas generation to increase. This behavior could be also observed with the coke $\mathrm{C}$. These results indicate that this $\mathrm{CO}$ gas generation is caused by the gasification of carbon. To discuss the temperature dependence of gasification, the temperature at which the rate of CO gas generation reaches $10 \mu \mathrm{mol} / \mathrm{s} \cdot \mathrm{g}$-carbon is defined as the starting temperature of gasification. Nomura et al. ${ }^{11)}$ defined the temperature as that at which the rate of weight change reaches $0.002 \mathrm{~min}^{-1}$ under the gas condition of $\mathrm{CO}: \mathrm{CO}_{2}=1: 1$. Converting this rate to the same unit of this study, it was approximately $0.06 \mu \mathrm{mol} / \mathrm{s} \cdot \mathrm{g}$-carbon because they used the sample of 100 g. In this study, the rate at the starting temperature of gasification is one hundred times higher than the rate at the reaction starting temperature reported by Nomura et al. These values cannot be so simply compared because the experimental conditions such as the atmosphere, sample weight, and so on are different. However, the ratio of the maximum rate of gasification to the rate at the start of the reaction and at the starting temperature is approximately 3 and 5, respectively. Compared with the difference of the weight change rate, these ratio values are similar. Figure 11

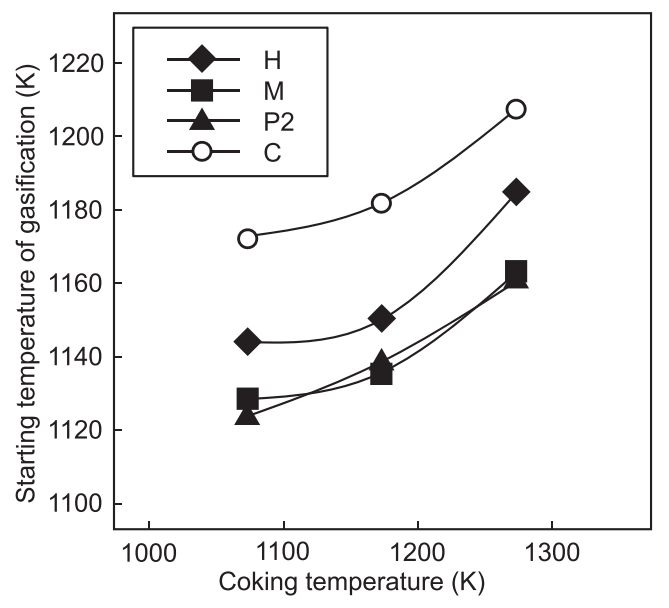

Fig. 11. Relation between starting temperature of gasification and coking temperature of coke with and without iron ore.

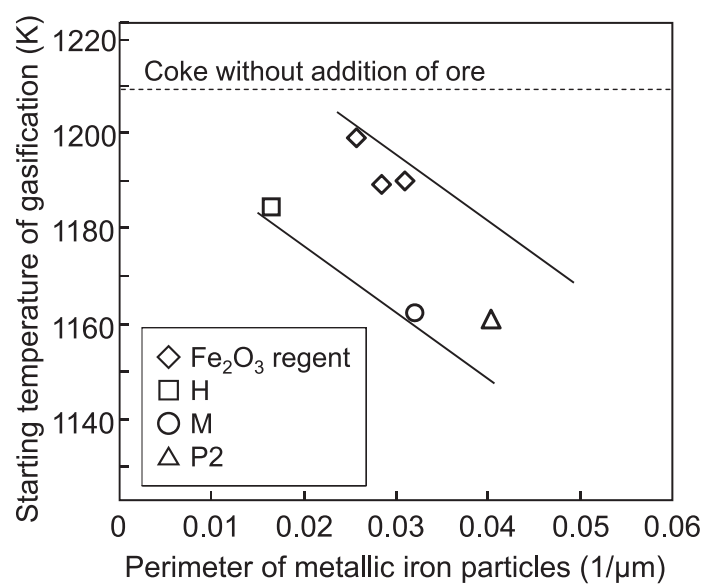

Fig. 12. Relation between starting temperature of gasification and perimeter of metallic iron particles.

shows the relation between the starting temperature of gasification and the coking temperature of coke prepared from coal with and without iron ore. The gasification temperature obtained in this study is lower than that reported by Nomura et al. The reason is that their coking condition at $1523 \mathrm{~K}$ for $66.6 \mathrm{ks}$ is higher and longer, respectively, than that in this study. The starting temperature of gasification for the cokes prepared under all conditions increases with an increase in the coking temperature. These have same temperature dependence due to the properties of carbon, such as crystallization after carbonization. The starting temperature of the iron coke with $\mathrm{H}$ ore is $30 \mathrm{~K}$ lower than that of coke $\mathrm{C}$ at every coking temperature. The starting temperature of the iron coke with $\mathrm{M}$ and $\mathrm{P} 2$ ores is $20 \mathrm{~K}$ lower than that with $\mathrm{H}$ ore, even though there is no effect of the coking temperature. The metallic iron formed after the carbonization of coal with $\mathrm{M}$ and $\mathrm{P} 2$ ores has finer particles than that obtained using $\mathrm{H}$ ore, as shown in Fig. 9. It is possible that such lowering of the starting temperature is caused by the large specific surface area that is affected to the catalytic reaction of carbon gasification by metallic iron. A gasification test of the iron coke that was carbonated using coal and $\mathrm{Fe}_{2} \mathrm{O}_{3}$ reagent at $1273 \mathrm{~K}$ was carried out. The perimeter and average size of the metallic iron particles in the iron coke was measured by image analysis. The effects of the perim- 


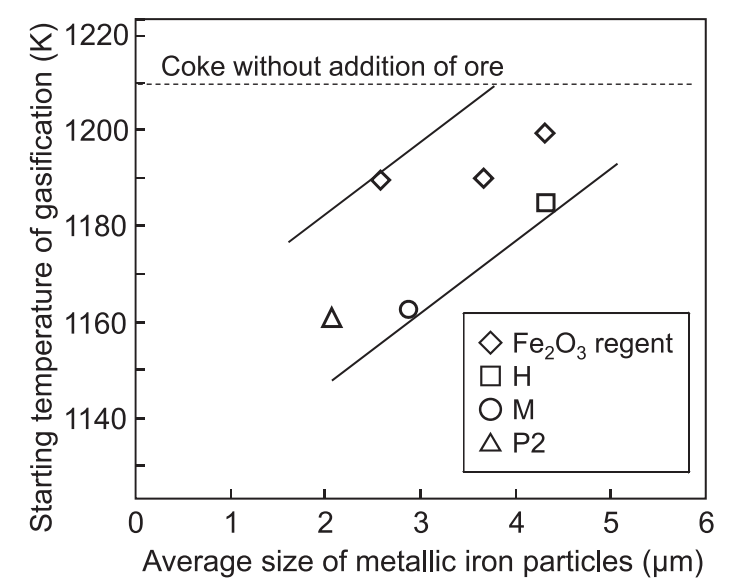

Fig. 13. Relation between starting temperature of gasification and average size of metallic iron particles.

eter and the average size of the metallic iron particles on the starting temperature of gasification are shown in Figs. 12 and 13, respectively. The starting temperature decreases with increasing perimeter and decreasing average size. There is no difference between the iron and reagent. These results indicate that the effect of the specific surface of metallic iron on the temperature at which gasification begins is strong. Accordingly, it concludes that the lowering of the starting temperature of the gasification of iron coke is caused by an increase in the specific surface area of the metallic iron formed during carbonization.

\section{Conclusions}

The effects of the particle size of iron ore in the composite and the mixture ratio of coal to iron ore on both reduction and gasification behaviors were evaluated. The effects of the iron ore type and the particle size of iron ore on the temperature at which gasification starts were studied. The following results were obtained.

(1) The temperature at which metallic iron starts to form in the composite decreased with a decrease in the particle size of the iron ore. The particle size dependence observed with the use of goethite ore containing high combined water was smaller than that with the use of hematite ore. This result was caused by the nano-sized porous structure of the goethite ore after dehydration. There was no relation between the temperature at which the reduction degree reaches $80 \%$ and the type of the iron ore. Furthermore, no effect of the particle size of iron ore on this temperature could be observed when the particle size became less than $20 \mu \mathrm{m}$.

(2) The concentration of $\mathrm{CO}$ and $\mathrm{H}_{2}$ gas generated from the composite increased with increasing the amount of coal in the composite. Therefore, the temperature at which metallic iron starts to form becomes lower. The $\mathrm{C} / \mathrm{O}$ dependence of the composite using hematite ore had a stronger effect than that using goethite ore which has high combined water content.

(3) The $\mathrm{C} / \mathrm{O}$ dependence of the composite using hematite ore has stronger effect than that using high combined water ore.

(4) Assuming that the temperature at which the rate of $\mathrm{CO}$ gas generation reaches $10 \mu \mathrm{mol} / \mathrm{s} \cdot \mathrm{g}$-carbon is defined as the starting temperature of gasification, this temperature of the iron coke using hematite and high combined water content ores was approximately $30 \mathrm{~K}$ and $50 \mathrm{~K}$ lower, respectively, than that of coke without the ore addition. The coking temperature had a small effect on the starting temperature of gasification.

(5) The starting temperature of gasification decreases with an increase in the perimeter, which correspond to surface area in case of 3D expression, of the metallic iron formed after carbonization and a decrease in the average particle size of the formed metallic iron. These results indicate that the decrease in the starting temperature of gasification is caused by an increase in the specific surface area, which has a catalytic effect on the gasification process.

\section{Acknowledgments}

The authors would like to thank Mr. Takeshi Nishimura and Dr. Chen Hui for their help with the reduction experiment and the observation of microstructures. This study was supported in part by a grant for the promotion of research, Grant-in-Aid for Scientific Research (A) [No.20246111], from the Japan Society for the Promotion of Science, and from the Steel Industry Foundation for the Advancement of Environmental Protection Technology.

\section{REFERENCES}

1) M. Kundak, L. Lazić and J. Črnko: Metalurgija, 48 (2009), 193.

2) S. Watakabe, K. Takeda, H. Nishimura, S. Goto, N. Nishimura, T. Uchida and M. Kiguchi: Tetsu-to-Hagané, 92 (2006), 901.

3) S. Nomura, H. Terashima, E. Sato and M. Naito: Tetsu-to-Hagané, 92 (2006), 849.

4) A. Kasai, M. Naito, Y. Matsui and Y. Yamagata: Tetsu-to-Hagané, 89 (2003), 1212.

5) S. Kondo and S. Aoyama: Tetsu-to-Hagané, 59 (1973), S23.

6) K. Nagano: Tetsu-to-Hagané, 90 (2004), 51.

7) J. Okazaki, K. Higuchi and M. Nakano: Shin-nittetsu-Giho, 384 (2006), 20.

8) T. Murakami, T. Nishimura and E. Kasai: ISIJ Int., 49 (2009), 1686.

9) Y. Kashiwaya, S. Nakaya and K. Ishi: Tetsu-to-Hagané, 77 (1991), 759

10) K. Watanabe, S. Ueda, R. Inoue and T. Ariyama: ISIJ Int., 50 (2010), 524.

11) S. Nomura, K. Higuchi, K. Kunitomo and M. Naito: Tetsu-toHagané, 95 (2009), 813. 